\title{
A NEW SPECIES OF PRAYING MANTIS FROM INDIA
}

\author{
M.C. Vyjayandi ${ }^{1}$ and T.C. Narendran ${ }^{2}$ \\ ${ }^{1}$ Department of Zoology, Providence Women's College, Calicut, Kerala 673009, India \\ 2 (corresponding author) Department of Zoology, University of Calicut, Kerala 673635, India \\ Email: ${ }^{2}$ drtcnarendran@yahoo.com
}

\begin{abstract}
A new species of Amantis is described from Kozhikode, Kerala, India. Characteristic differences between the other species is provided.
\end{abstract}

KEYwords
Amantis malabarensis $\begin{gathered}\text { sp. nov., Kerala, Mantodea, new } \\ \text { species }\end{gathered}$

Abbreviations

DZCU - Department of Zoology, Calicut University

The genus Amantis was erected by Giglio-Tos in 1915 with type species Amantis reticulata. Five species of Amantis are already known from India, viz., Amantis biroi Giglio-Tos, A. saussurei (Boliver), A.subirina Giglio-Tos, A. bolivarii GiglioTos, A. indica Giglio-Tos. A new species, Amantis malabarensis sp. nov., is described in this paper from Kozhikode, Kerala.

The specimens were collected by hand. The observations were made using $\mathrm{M}_{3} \mathrm{Z}$ Wild Stereozoom (Switzerland) microscope and the figures were drawn using the drawing tube of $M_{3} Z$ Wild Stereozoom (Switzerland) microscope

\section{Amantis malabarensis sp. nov.}

(Figs.1-7)

\begin{abstract}
Materials examined
Holotype: Male, 21-v-2000, Kovoor (Kozhikode), Kerala, India, coll. Vyjayandi, DZCU.

Paratypes: 1 male, 18-ii-2000, Malaparamba (Kozhikode), Kerala, coll. Vyjayandi, DZCU; 1 male, 21-iii-99, Malaparamba (Kozhikode), Kerala, coll. Grace, DZCU; 1 male, 5-x-2001, Calicut University campus, Kerala, coll. Vyjayandi, DZCU.
\end{abstract}

Male: Body length $14 \mathrm{~mm}$.

Colour: Black with orange tinge. Head central area of vertex black, either side clay brown with fuscous tinge; eyes brown to glossy fuscous; ocelli, frontal sclerite, forecoxa, forefemur and clypeus orange brown. Pronotum dorsally black. Forefemoral spines black at apex only; tibia, metatarsus black; other tarsal segments testaceous; middle and hind coxa black; femur, tibia, metatarsus and other tarsal segments testaceous. Wings testaceous to black, semi hyaline, with smokey stiff hairs. Metasoma black.

Head: Broadly triangular, 1.6x wider than high; vertex with five insignificant lobes; eyes globular; ocelli large, conspicuous; frontal sclerite pentagonal, almost as wide as high, angular superiorly, slightly arched inferiorly, disc flat; clypeus projecting; antenna thick, with rosettes of sharp bristles at the junction of two segments.

Pronotum: A little shorter than forecoxa, rhomboidal, supra coxal dialation pronounced; metazona constricted at middle, disc smooth with insignificant carina; $1.4 x$ longer than broad at supra coxal dialation; metazona $1.2 x$ longer than prozona, margin setaceous; forelegs simple, not foliaceous; coxa with mid dorsal carina; margin with hairs; femur 1.3x longer than coxa, 1.9x longer than tibia with four external, four discoidal and 12 internal (6 long and 6 short) spines; disc between rows of external and internal spines denticulated; tibia $1.4 x$ longer than metatarsus with 11 external and 11 internal spines; metatarsus slightly longer than all other tarsal segments together; middle and hind legs: middle leg shorter than the hind leg; femur as equal as tibia; tibia more setaceous than femur; hind metatarsus a little longer than the other tarsal segments together; wings semihyaline, setaceous; fore wings costal area opaque, costal vein setaceous, anterior and posterior radial veins not bifurcating, discoidal vein bifurcate distally; hind wings anterior vein bifurcates and posterior radial vein trifurcates.

Metasoma: Shorter than wings, stout, fusiform; supra anal plate short; posterior part subconical; cerci short, segmented, posterior part with pubescence.

\section{Discussion}

This species Amantis malabarensis sp. nov. is closely related to Amantis biroi Giglio-Tos in the following characters: pronotum, forewing and veins black. Amantis malabarensis sp. nov. differs from it in the following characters: (1) frontal sclerite without black spot (frontal sclerite with black spot $A$. biroi); and (2) pronotum with continuous black stripe (pronotum with discontinuous black stripe in A. biroi).

The new species resembles A. bolivarii Giglio-Tos in the following characters: (1) frontal sclerite without any black stripe; (2) pronotum with median black stripe; and (3) wings subhyaline. It differs from A. bolivarii Giglio-Tos in following features: (1) forecoxa internally without black spot (forecoxa internally with black spot in A. bolivarii ); and (2) forefemur without any black dots internally (forefemur internally with 2-3 dots in $A$. bolivarii).

Amantis malabarensis sp. nov. is similar to Amantis indica Giglio-Tos in the following characters: (1) frontal sclerite without any black patch; (2) pronotum with a black stripe; and (3) foremetatarsus black, other tarsal segments brown. This species differs from A. indica in the following character: (1) forefemur not black, without any indistinct black bands (forefemur black, 

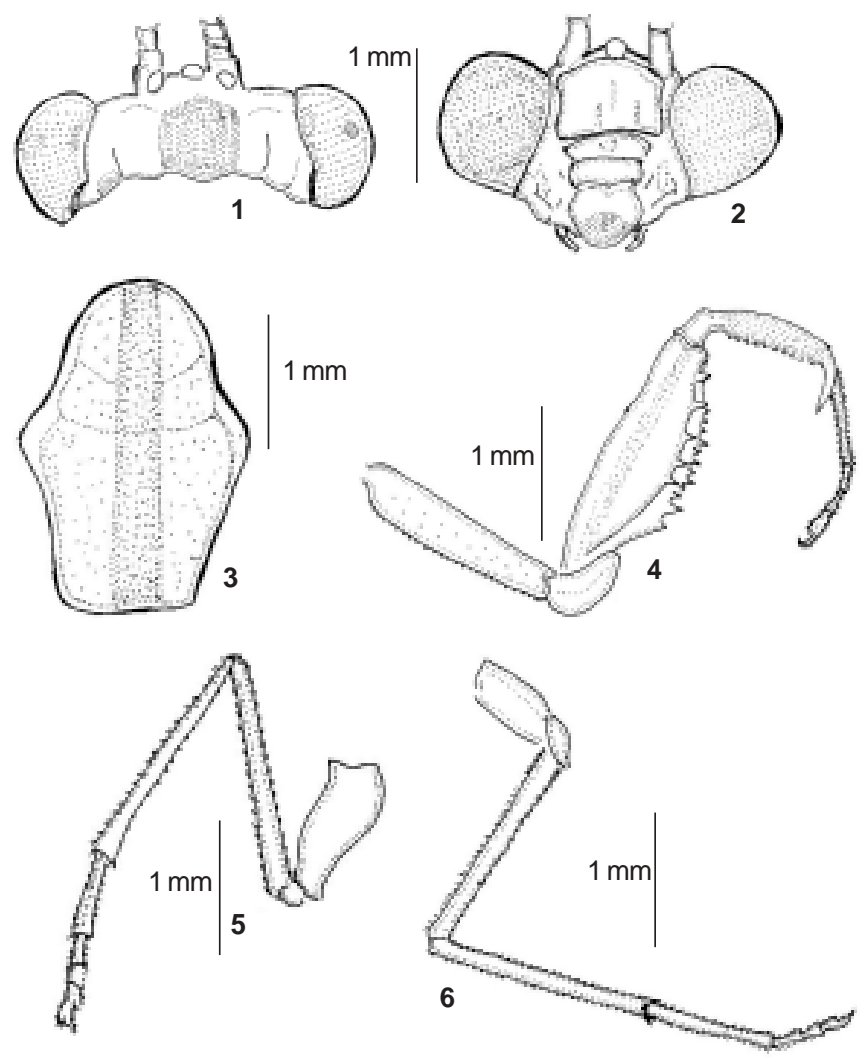

Figures 1-6. Amantis malabarensis sp. nov.

1 - Head (dorsal view); 2 - Head (ventral view); 3 - Pronotum; 4 - Fore leg; 5 - Mid leg; 6 - Hind leg

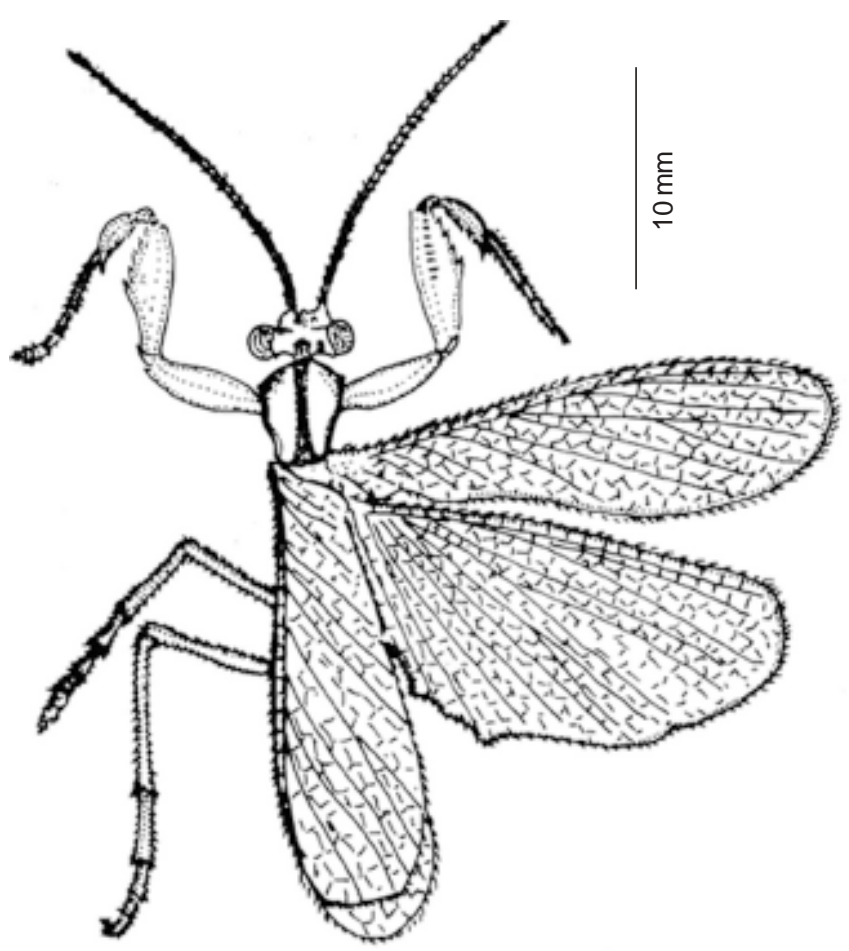

Figure 7. Amantis malabarensis sp. nov. (entire) with 3 indistinct bands in $A$. indica).

Amantis malabarensis sp. nov. resembles Amantis saussurei Bolivar in the following characters: (1) vertex dorsally blackish; and (2) pronotum with a dark median line. Amantis malabarensis sp. nov. differs from Amantis saussurei Bolivar in the following characters: (1) frontal sclerite without black dots (Frontal sclerite with two black spots on either side in $A$. saussurei Bolivar); and (2) first fore tarsal segment black (First tarsal segment brown in A. saussurei).

Amantis malabarensis sp. nov. is similar to Amantis subirina Giglio-Tos in the following characters: (1) frontal sclerite without any black spot; (2) pronotum with median black stripe; and (3) forecoxa brown. Amantis malabarensis sp. nov. differs from Amantis subirina in the following characters: (1) vertex with median black stripe (without any black stripe in A. subirina); (2) forelegs femur brown (forefemur black with three indistinct bands in A. subirina); and (3) second tarsal segment not black (second tarsal segment black in A. subirina).

\section{REFERENCES}

Giglio-Tos, E. (1915). Mantidi Esotici genere e specie nuove. Bulletin of Social Entomology Italiana 46: 151-154.

Mukherjee, T.K., A.K. Hazra and A.K. Ghosh (1995). The Mantid Fauna of India (Insecta: Mantodea). Oriental Insects 29: 263-266.

\section{ACKNOWLEDGEMENT}

We thank the Calicut University authority for laboratory facilities provided. The first author is thankful to the University Grants Commission for the teacher fellowship under Faculty Improvement Programme (2001-2002).

\section{m}

\section{Proceedings of The National Symposium on Bioresources, Biotechnology and Bioenterprise \\ organised by the Department of Zoology, Osmania University, Hyderabad} 19-21 November 2003

\section{has been published!}

\section{Editor: Professor K. Shankaraiah}

It includes 36 papers in Bioresource, 14 papers in Biotechnology and 26 papers in Bioenterprise. Published in March 2004, the xxiii+451-page A4 book costs Rs. 300.00 .

Copies can be ordered from:

Mr. T. Srikant, T-2 Sai Dwarkamai Apartments, Plot No. 8 \& 9 , Chitta Reddy Colony, New Bowenpally, Secunderabad, Andhra Pradesh, 500011.

Payment can be made by DD payable at Secunderabad. 